\title{
Interpenetrating Polymer Networks Based on Castor Oil IX.
}

\author{
Mayur PATEL and Bhikhu SUTHAR \\ Chemistry Department, Sardar Patel University, \\ Vallabh Vidyanagar, 388 120, Gujarat, India
}

(Received April 20, 1987)

\begin{abstract}
Crosslinked polyurethanes were obtained when trifunctional - OH group containing castor oil was reacted with difunctional toluene-2,4-diisocyanate under different stoichiometric conditions varying $\mathrm{NCO} / \mathrm{OH}$ ratio. These polyurethanes swelled in $n$-butyl acrylate monomer and subsequently polymerized by radical polymerization initiated with benzoyl peroxide in presence of crosslinking agent ethylene glycol dimethacrylate. A series of interpenetrating networks, PU/PnBA IPNs, were obtained as tough films by transfer moulding. All these IPNs films were characterized by resistance to chemical reagents, thermal behavior (DSC, TG), and mechanical studies such as tensile strength, Young's modulus, elongation at break $(\%)$ and hardness shore $A$. The mechanothermal (DMA) and morphological (SEM) behavior were studied. Dielectric properties such as electrical conductivity, dielectric constant $\left(\varepsilon^{\prime}\right)$, dielectric loss $\left(\varepsilon^{\prime \prime}\right)$, and dielectric loss tangent $(\tan \delta)$ were estimated.

KEY WORDS Crosslinked Polyurethane / Interpenetrating Polymer Networks / Crosslinker Ethylene Glycol Dimethacrylate / Mechanothermal Study / Scanning Electron Microscopy / Dielectric Properties /
\end{abstract}

After historical synthesis of IPN by Millar ${ }^{1}$ and the pioneering works of Sperling, ${ }^{2-5}$ Frisch, ${ }^{6-9}$ and Hourston, ${ }^{10-13}$ IPNs have been of great technological importance. Castor oil-a triglyceride containing ricinoleic acid has been reported in the literature being used in many polyurethane based formulations for various engineering applications. ${ }^{14,15}$ However, few reports are available regarding the use of castor oil for making processable polyurethane elastomers. Sperling and his cowork$\mathrm{ers}^{16-18}$ reported a series of IPNs from castor oil based polyurethanes and polymerizing styrene monomer in the presence of divinyl benzene as a crosslinker. They found that the IPNs were tough plastics or reinforced elastomers depending on composition. With a view to investigating such potentialities, we undertook the synthesis of novel IPNs based on castor oil. ${ }^{19-23}$ The present investigation deals with the synthesis of IPNs from a swelled crosslinked polyurethanes (from castor oil and toluene-2,4-diisocyanate) and poly( $n$-butyl acrylate) containing ethylene glycol dimethacrylate crosslinker. The PU/PnBA IPNs films were characterized by their resistance to chemical reagents, thermal stabilities (DSC, TG, and mechanical studies such as tensile strength, Young's modulus, elongation at break (\%) mechanothermal (DMA), morphological (SEM) behavior, and dielectric properties.

\section{EXPERIMENTAL}

\section{Materials}

Materials used are summarized in Table I.

\section{Synthesis of Polyurethane}

Castor oil ( $55 \mathrm{~g}, 0.055 \mathrm{~mol})$ was reacted with toluene-2,4-diisocyanate $(17.38 \mathrm{~g}, 0.099 \mathrm{~mol})$ in order to maintain $\mathrm{NCO} / \mathrm{OH}$ ratio 1.6. This mixture was stirred for one hour at $45^{\circ} \mathrm{C}$. The polymer was isolated as a thick liquid. The 
structural evidence comes from IR spectrum as described previously. ${ }^{16}$ Following the above procedure, the other polyurethanes (PU) with varying ratio of $\mathrm{NCO} / \mathrm{OH}$ were prepared.

\section{Synthesis of IPNS}

A crosslinked polyurethane as prepared above $(25 \% \mathrm{w} / \mathrm{w})$ was swollen in the monomer $n$-butyl acrylate containing $1 \%$ ethylene glycol dimethacrylate $(75 \% \mathrm{w} / \mathrm{w})$. To this mixture benzoyl peroxide $(0.5 \% \mathrm{w} / \mathrm{w})$ was added to initiate the polymerization. The reaction mixture was stirred at room temperature for five minutes to form a homogeneous solution. The temperature was then raised to $60^{\circ} \mathrm{C}$ to initiate $n$-butyl acrylate polymerization along with added crosslinker. After stirring for one hour, the solution was poured into a glass mould kept in an air circulating oven maintained at $60^{\circ} \mathrm{C}$. It was kept at this temperature for 24 hours and at $120^{\circ} \mathrm{C}$ for 4 hours. The film thus formed was cooled slowly and removed from the mould. Nine different IPNs were synthesized with different composition and abbreviated as IPN-1 to IPN-9. The compositions used are summarized in Table $\mathrm{I}$.

\section{Characterization}

Resistance to chemical reagents were made according to ASTM D 543-67 (1978). Tensile properties were measured on a universal Instron testing machine according to ASTM D 638 (1977). Hardness shore $A$ was measured according to ASTM D 785 (1965). Dielectric properties were measured according to ASTM D 1531 (1962). DSC measurements were made on a Du Pont 900 thermal analyzer at a heating rate of $10^{\circ} \mathrm{C} \mathrm{min}^{-1}$ in air. The thermal stability was measured on a Du Pont 951 thermal analyzer at a heating rate of $10^{\circ} \mathrm{Cmin}^{-1}$ in air. SEM (scanning electron microscope) observations were made with a Phillips EM-400 equipped with a S(T) EM System PW-6585 as a scanning attachment. The cryogenically fractured sample (liquid nitrogen) was mounted vertically on a SEM stub using silver adhesive paste. The specimen was coated with gold using the vacuum system EP 5/Carl Zeiss at about $10^{-5}$ Torr. The mechanothermal analysis was made on $\mathrm{Du}$ Pont 981 dynamic mechanical analyzer at a heating rate of $5^{\circ} \mathrm{Cmin}^{-1}$ and frequency $10 \mathrm{mV} \mathrm{cm}^{-1}$.

\section{RESULTS AND DISCUSSION}

\section{Preparation of PU/PnBA IPNs}

All the IPNs, (IPN-1 to IPN-9), were obtained as tough films and compositional variation presented in Table II. The poly-

Table I. Materials used

\begin{tabular}{|c|c|c|c|}
\hline Materials & Description & Source & Code \\
\hline Castor oil & $\begin{array}{l}\text { Triglyceride of ricinoleic acid, hydroxyl } \\
\text { value } 124,-\mathrm{OH}=2.27 \text { per mole of } \\
\text { castor oil }\end{array}$ & Local market & - \\
\hline Toluene-2,4-diisocyanate & $\begin{array}{l}\text { Density } 1.22 \mathrm{~g} \mathrm{ml}^{-1} \text {, containing } \\
80 \%+20 \% \text { toluene- } 2,6 \text {-diisocyanate }\end{array}$ & Fluka & TDI \\
\hline$n$-Butyl acrylate & Density $0.901 \mathrm{~g} \mathrm{ml}^{-1}$ & Schuchardt M & $n$-BA \\
\hline $\begin{array}{l}\text { Ethylene glycol } \\
\text { dimethacrylate }\end{array}$ & Acrylic crosslinker & Schuchardt M & EGDM \\
\hline Benzoyl peroxide & $\begin{array}{l}\text { Initiator recrystallized } \\
\text { from chloroform }\end{array}$ & Aldrich & $\mathrm{Bz}_{2} \mathrm{O}_{2}$ \\
\hline Polyurethane & Polyurethane from castor oil + TDI & Our laboratory & PU \\
\hline
\end{tabular}


Table II. Data on feed composition (individual polyurethane (PU) and $n$-butyl acrylate) for IPN synthesis

\begin{tabular}{|c|c|c|c|c|}
\hline \multirow{2}{*}{$\begin{array}{c}\text { Sample } \\
\text { code }\end{array}$} & \multirow{2}{*}{$\begin{array}{l}\text { Content of } \\
\text { prepoly- } \\
\text { urethane } \\
\text { in wt } \% \text { a }\end{array}$} & \multirow{2}{*}{$\begin{array}{c}\text { Content of } \\
n \text {-butyl } \\
\text { acrylate } \\
\text { in wt } \%\end{array}$} & \multirow{2}{*}{$\begin{array}{c}\text { Density } \\
\mathrm{g} \mathrm{ml}^{-1}\end{array}$} & \multirow{2}{*}{$\frac{T_{\mathrm{g}}{ }^{\prime} \mathrm{s}^{\mathrm{c}}}{{ }^{\circ} \mathrm{C}}$} \\
\hline & & & & \\
\hline IPN-1 & 25 & 75 & 1.08 & 39 \\
\hline IPN-2 & $35(1.6)^{b}$ & 65 & 1.10 & 39 \\
\hline IPN-3 & 45 & 55 & 1.12 & 40 \\
\hline \multicolumn{5}{|c|}{$--\cdots----\cdots---\cdots-\cdots-\cdots$} \\
\hline IPN-4 & 25 & 75 & 1.17 & 41 \\
\hline IPN-5 & $35(1.8)^{b}$ & 65 & 1.15 & 40 \\
\hline IPN-6 & 45 & 55 & 1.13 & 40 \\
\hline \multicolumn{5}{|c|}{$-------\cdots---\cdots-\cdots-\cdots$} \\
\hline IPN-7 & 25 & 75 & 1.14 & 39 \\
\hline IPN-8 & $35(2.0)^{b}$ & 65 & 1.20 & 41 \\
\hline IPN-9 & 45 & 55 & 1.13 & 41 \\
\hline
\end{tabular}

a Contents of polyurethanes $>45 \mathrm{wt} \%$ is not possible due to experimental difficulties.

b Values in bracket indicate $\mathrm{NCO} / \mathrm{OH}$ ratio of castor oil and toluene-2,4-diisocyanate.

c From DSC measurements at a heating rate of $10^{\circ} \mathrm{C} \min ^{-1}$ in air.

urethanes obtained from castor oil and toluene-2,4-diisocyanate were characterized according to previous report. ${ }^{16}$ It was found that the condensation of the trifunctional $-\mathrm{OH}$ containing castor oil and difunctional toluene2,4-diisocyanate yielded polyurethane of highly crosslinked swollen mass. It was insoluble in common organic solvents and therefore could not be characterized in terms of viscosity and molecular weight determination. It is worth mentioning that these gelled polyurethanes could not be characterized further in terms of thermal behavior, mechanical properties, dynamic mechanical spectroscopy, and dielectrical behavior. However, the crosslinked structure was already established by Sperling. ${ }^{12}$

The IPNs thus obtained as tough films were insoluble in all common organic solvents. The densities of the IPNs (Table II) were measured at room temperature using a hydrostatic technique. The densities varied according to composition.
Table III. Data from TG curves of IPNs

\begin{tabular}{lcccccc}
\hline & \multicolumn{5}{c}{$\begin{array}{c}\text { Percent weight loss }( \pm 2 \%) \text { at } \\
\text { different temperature }\left({ }^{\circ} \mathrm{C}\right)\end{array}$} \\
\cline { 2 - 7 } Sample code & 300 & 350 & 400 & 450 & 500 & 550 \\
\hline IPN-1 & 6 & 30 & 57 & 72 & 86 & 94 \\
IPN-2 & 4 & 29 & 57 & 70 & 85 & 96 \\
IPN-3 & 5 & 30 & 56 & 72 & 85 & 96 \\
IPN-4 & 4 & 31 & 57 & 72 & 84 & 94 \\
IPN-5 & 6 & 28 & 55 & 71 & 85 & 95 \\
IPN-6 & 6 & 30 & 56 & 70 & 86 & 95 \\
IPN-7 & 5 & 29 & 54 & 69 & 86 & 94 \\
IPN-8 & 5 & 31 & 57 & 70 & 84 & 96 \\
IPN-9 & 6 & 31 & 56 & 72 & 85 & 96 \\
Homopolymer & 7.2 & 34 & 82 & 96.2 & - & - \\
$\quad$ PnBA & & & & & & \\
\hline
\end{tabular}

\section{Resistance to Chemical Reagents}

Solvent resistance of PU/PnBA IPN films to a series of standard reagents has studied. It was observed that these IPNs are stable in all standard reagents but become brittle and lose their gloss in methyl ethyl ketone, toluene and carbon tetrachloride.

\section{Thermal Behavior}

Frisch and his coworkers ${ }^{24-26}$ studied the thermal behavior of various IPNs and found that these IPNs to possess greater thermal stability than their component networks. In the present study the thermal behavior of IPN1 to IPN-9 was studied and compared with the homopolymer of $n$-butyl acrylate in terms of $\%$ loss in weight at different temperatures from their TG curves and the results are reported in Table III. It is evident from the observations that all the IPNs are stable upto $300^{\circ} \mathrm{C}$ and lose weight rapidly around $400^{\circ} \mathrm{C}$ and decompose completely beyond $550^{\circ} \mathrm{C}$. However, the thermal stability of none of the IPNs changes appreciably with increase in the contents of TDI in PU and contents of $\operatorname{poly}(n-$ butyl acrylate) in the IPN sample. A comparison of the TG curves revealed that the thermal stability of IPN is much greater than that of the homopolymer of $n$-butyl ac- 
rylate. The enhancement in temperature for weight retention of IPNs may be explained on the basis of the miscibility of the two component networks. $^{2 \text {, }}$

Differential scanning calorimetry of all the IPNs indicated glass transition temperatures around $40^{\circ} \mathrm{C}$. The data of glass transition temperatures of the IPNs are presented in Table II. $T_{\mathrm{g}}$ 's of all IPNs are compared with that of homopolymer of $n$-butyl acrylate. Literature reports the $T_{\mathrm{g}}$ of the homopolymer is around $-56^{\circ} \mathrm{C} .{ }^{28}$

\section{Mechanical Properties}

Sperling and his coworkers ${ }^{29,30}$ reported the synergistic behavior of polystyrene and poly( $n$-butyl acrylate) in the IPNs of PS/PnBA. They found excellent mechanical properties superior to the individual homopolymers. ${ }^{29,30}$ They observed that in the IPNs, the component network which is crosslinked first, dominates the ultimate properties. This is due to the fact that the first network formed is swollen, so that its chains have an extended rigid configuration while the chains of component network II should be much more relaxed. The mechanical properties such as tensile strength, Young's modulus, elongation at break ( $\%$ ) and hardness shore $A$ of the IPNs in present study are presented in Table IV. Table IV reveals that IPNs exhibit good mechanical properties compared to their individual component networks I and II. Component network $I$ is a swollen crosslinked polyurethane which is elastomeric in nature and has been used in liquid phase in this investigation. Interpenetration of this liquid polyurethane with $n$-butyl acrylate monomer results in hard elastomeric films. Increase in the polyurethane content in the IPN increases the extent of crosslinking in IPN and dominates the overall behavior of IPNs. Incorporation of polyurethane as a separate phase in the $\operatorname{poly}(n-$ butyl acrylate) matrix of IPNs improved the mechanical properties. Thus it is observed that the IPNs obtained from elastomeric PU and
Table IV. Data on the mechanical properties of IPNs

\begin{tabular}{|c|c|c|c|c|}
\hline \multirow{2}{*}{$\begin{array}{l}\text { Sample } \\
\text { code }\end{array}$} & $\begin{array}{l}\text { Tensile } \\
\text { strength }\end{array}$ & $\begin{array}{c}\text { Tensile } \\
\text { modulus }\end{array}$ & \multirow{2}{*}{$\begin{array}{l}\% \text { Elongation } \\
\text { at break }\end{array}$} & \multirow{2}{*}{$\begin{array}{c}\text { Hardness } \\
\text { shore } A\end{array}$} \\
\hline & $\mathrm{MN} \mathrm{m}^{-2}$ & $\mathrm{MN} \mathrm{m}^{-2}$ & & \\
\hline IPN-1 & 2.92 & 2.35 & 148 & 76 \\
\hline IPN-2 & 3.69 & 2.68 & 163 & 79 \\
\hline IPN-3 & 3.24 & 2.41 & 137 & 75 \\
\hline IPN-4 & 7.64 & 3.31 & 204 & 65 \\
\hline IPN-5 & 7.29 & 179 & 74 & \\
\hline IPN-6 & 8.47 & 4.85 & 198 & 80 \\
\hline IPN-7 & 10.14 & 5.30 & 194 & 78 \\
\hline IPN-8 & 10.82 & 6.25 & 183 & 77 \\
\hline IPN-9 & 11.15 & 5.11 & 188 & 71 \\
\hline \multicolumn{5}{|l|}{$\begin{array}{l}\text { Homo- } \\
\text { polymer }\end{array}$} \\
\hline PnBA & 60.4 & 2300 & 28 & 90 \\
\hline
\end{tabular}

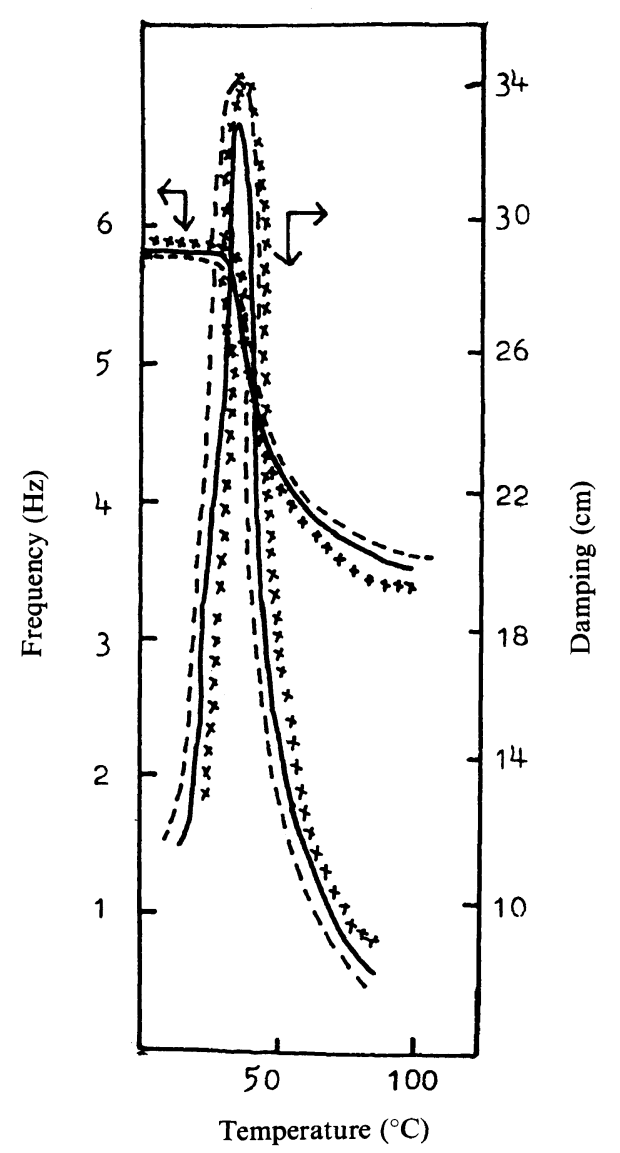

Figure 1. Frequency $(\mathrm{Hz})$ and Damping $(\mathrm{cm})$ vs. temperature: IPN-2 (-----); IPN-6 $(\times \times \times \times)$; IPN-9 (-). 


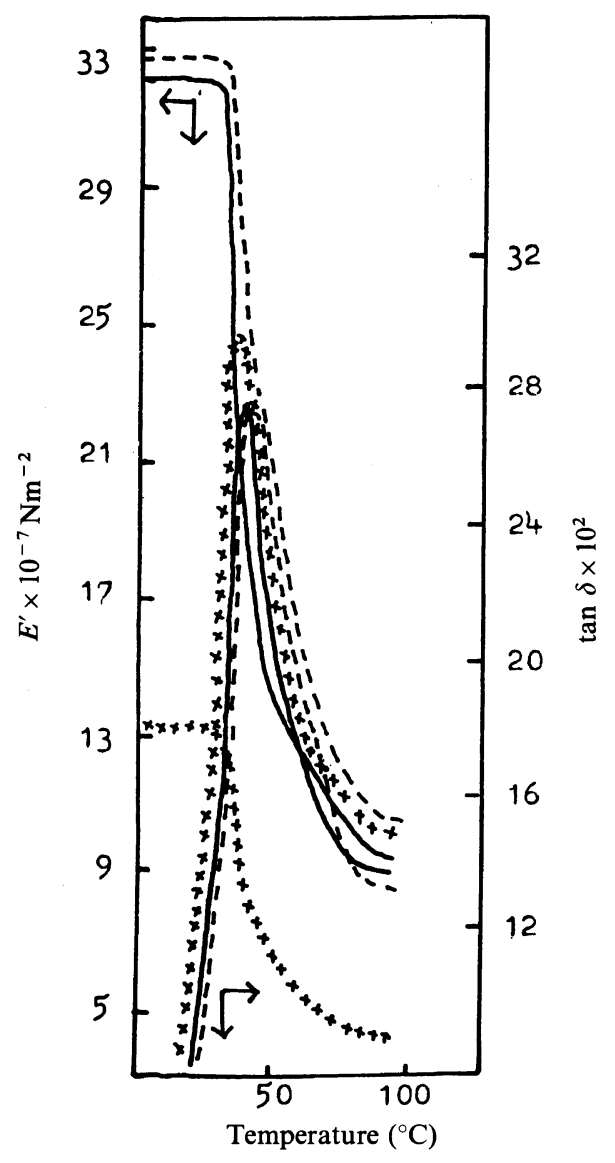

Figure 2. Storage modulus $\left(E^{\prime}\right)$ and damping factor $(\tan \delta)$ vs. temperature: IPN-2 (-----); IPN-6 $(\times \times \times \times)$; IPN-9 (-).

PnBA, have quite different properties from their individual polymers. This supports further the observations made by earlier workers. ${ }^{4}$ The dynamic mechanical properties of IPN-2, IPN-6, and IPN-9 are shown in Figures 1,2 , and 3 . The dynamic storage modulus $\left(E^{\prime}\right)$ $v s$. temperature for the IPNs shows that the general modulus responds to $n$-butyl acrylate concentration and temperature. In damping factor $(\tan \delta) v s$. temperature for these IPNs showed one peak corresponding to only one $T_{\mathrm{g}}$ of the combined interpenetrated PU and PnBA polymers. The $T_{\mathrm{g}}$ of the homopolymer of $n$-butyl acrylate is below $0^{\circ} \mathrm{C}$ and thus it was not compared in the present study. The mor-

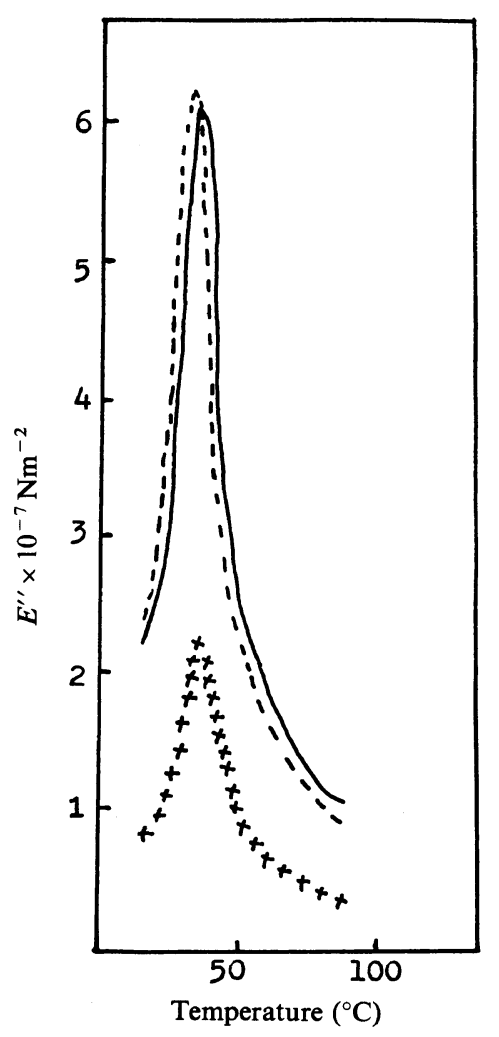

Figure 3. Loss modulus $\left(E^{\prime \prime}\right)$ vs. temperature: IPN-2 (----); IPN-6 $(\times \times \times \times)$; IPN-9 (-).

Table V. Data on the electrical conductivity of the IPNs

\begin{tabular}{|c|c|c|c|}
\hline $\begin{array}{c}\text { Sample } \\
\text { code }\end{array}$ & $\begin{array}{c}\text { Electrical } \\
\text { conductivity at } \\
\text { room temp }(\sigma)\end{array}$ & $\begin{array}{c}\text { Specific } \\
\text { conductivity } \\
\left(\sigma_{0}\right)\end{array}$ & $\begin{array}{l}\text { Activation } \\
\text { energy } E\end{array}$ \\
\hline & $\mathrm{Ohm}^{-1} \mathrm{~cm}^{-1}$ & $\mathrm{Ohm}^{-1} \mathrm{~cm}^{-1}$ & $\mathrm{~kJ} \mathrm{~mol}^{-1}$ \\
\hline IPN-2 & $8.7 \times 10^{-14}$ & $2.5 \times 10^{-12}$ & 31.3 \\
\hline IPN-6 & $1.8 \times 10^{-14}$ & $1.5 \times 10^{-12}$ & 38.3 \\
\hline IPN-9 & $4.3 \times 10^{-14}$ & $1.0 \times 10^{-12}$ & 38.3 \\
\hline
\end{tabular}

phological evidence of these IPNs comes from their SE micrographs at 1200 magnification as shown by micrographs of IPN-2, IPN-6, and IPN-9 in Figure 4. The observed inhomogeneity in each micrograph reveals the interpenetration of two different phase of PU and PnBA. However, the SE micrographs indicated the 


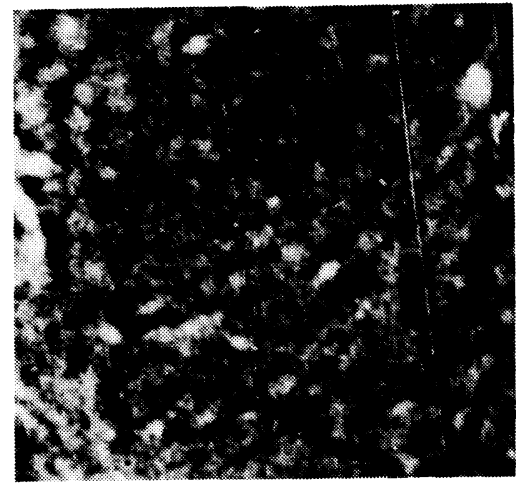

(a)

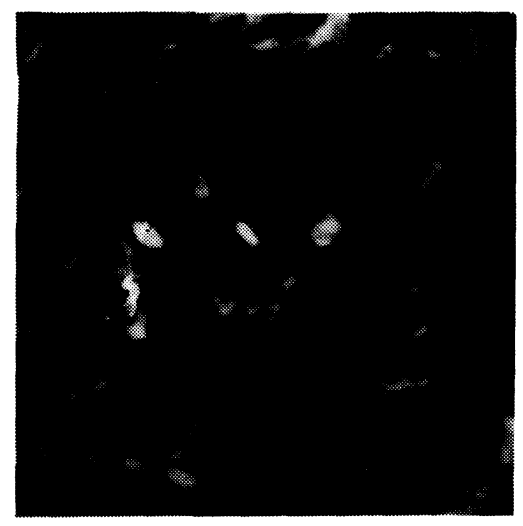

(b)

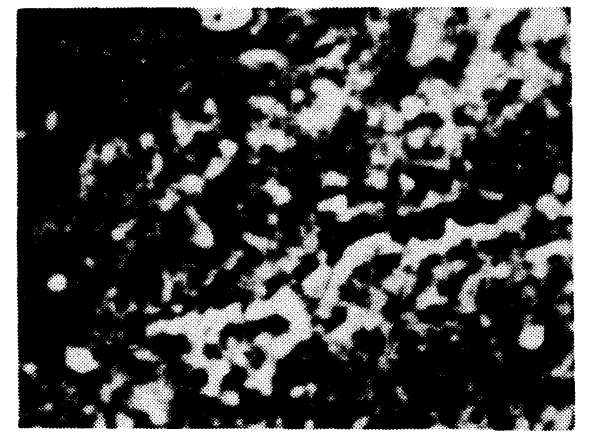

(c)

Scanning electron micrographs: (a) IPN-2 magnification 1200; (b) IPN-6 magnification 1200; (c) IPN-9 magnification 1200 .

Figure 4. Scanning electron micrographs of some IPNs.

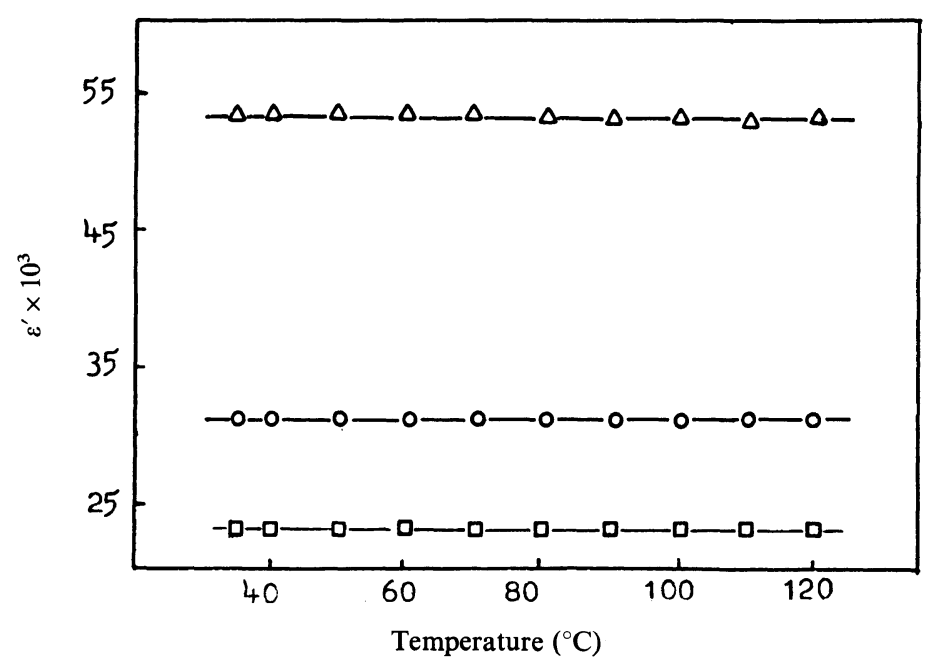

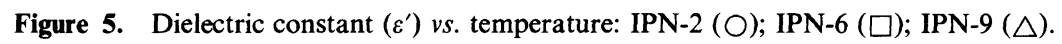


Interpenetrating Polymer Networks Based on Castor Oil IX.

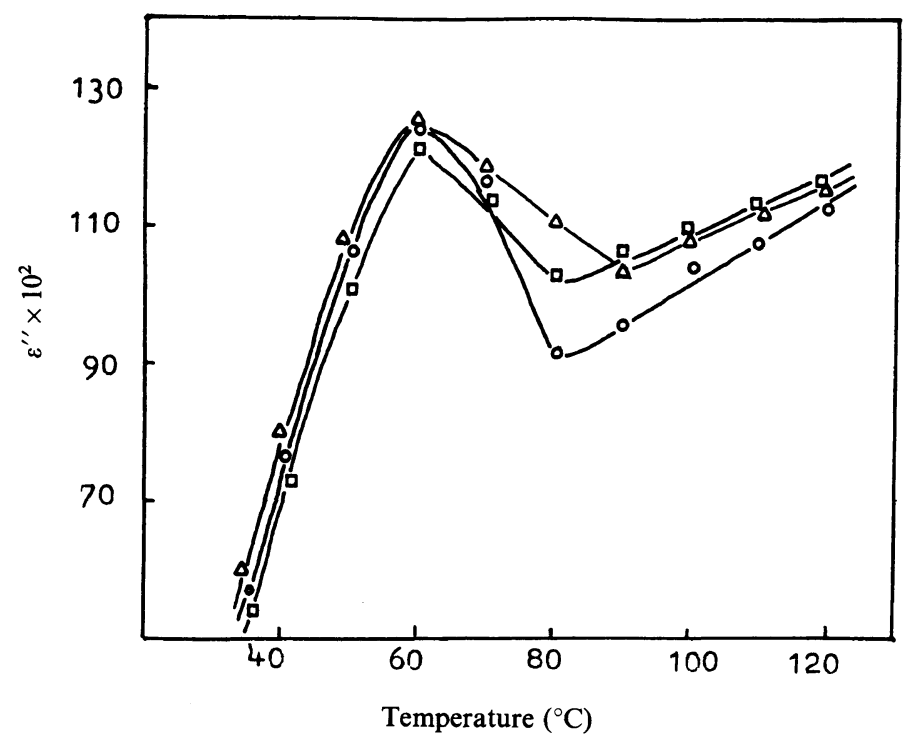

Figure 6. Dielectric loss $\left(\varepsilon^{\prime \prime}\right)$ vs. temperature: IPN-2 (O); IPN-6 ( $\left.\square\right)$; IPN-9 $(\triangle)$.

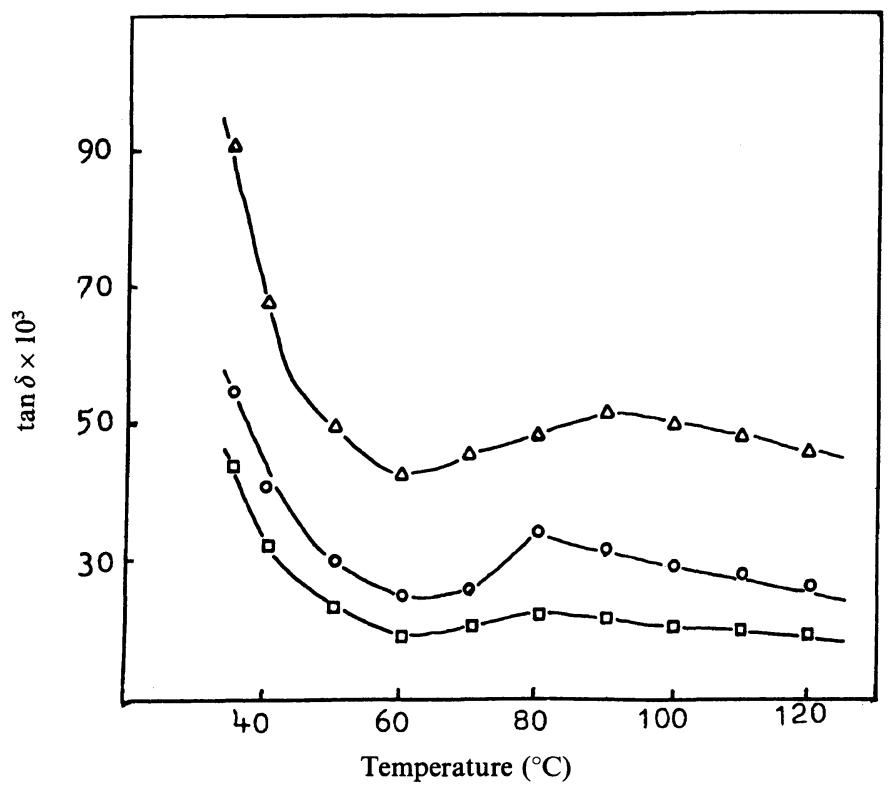

Figure 7. Loss tangent $(\tan \delta)$ vs. temperature: IPN-2 (O); IPN-6 ( $\square)$; IPN-9 $(\triangle)$.

phase separation containing predominant domain of polyurethane component over the domain of interpenetrated $\operatorname{poly}(n$-butyl acrylate).

\section{Electrical Properties}

The use of polymers in engineering as dielectrics has become increasingly popular and the choice mainly depends upon their dielectric properties. Frisch and his coworkers ${ }^{31}$ report- 
ed the dielectric properties of three component network of IPNs. IPNs of this present study were studied in terms of dielectrical properties. The specific electrical conductivity $\left(\sigma_{0}\right)$ electrical conductivity at room temperature $(\sigma)$ and the activation energy $(E)$ are given in Table V. The dielectrical properties $\left(\varepsilon^{\prime}, \varepsilon^{\prime \prime}\right.$, and $\tan \delta)$ at freqeuncy $(10 \mathrm{kHz})$ are shown in Figures 5-7. From these dielectrical properties, these IPNs behave exactly as insulators and have the bordering properties of semiconductors. $^{31}$

\section{REFERENCES}

1. J. R. Millar, J. Chem. Soc., 311 (1960).

2. L. H. Sperling and D. M. Friedman, J. Polym. Sci., $A-1,7,425$ (1969).

3. L. H. Sperling, D. A. Thomas, and A. A. Donatelli, "Recent Advances in Polymer Blends, Grafts and Blocks," Plenum Press, New York, N.Y., 1974.

4. L. H. Sperling, "Interpenetrating Polymer Networks and Related Materials," Plenum Press, New York, N.Y., 1981.

5. L. H. Sperling and J. M. Widmaier, Br. Polym. J., 16, 46 (1984).

6. H. L. Frisch, D. Klempner, and K. C. Frisch, J. Polym. Sci., B, 7, 775 (1969).

7. D. Klempner and H. L. Frisch, J. Polym. Sci., Polym. Lett. Ed., 8, 525 (1970).

8. D. Klempner and H. L. Frisch, "Polymer Alloys II," Plenum Press, New York, N.Y., 1980.

9. K. C. Frisch, D. Klempner, and H. X. Xiao, Polym. Eng. Sci., 25, 758 (1985).

10. D. J. Hourston and Y. Zia, J. Appl. Polym. Sci., 29, 629 (1984).

11. D. J. Hourston and Y. Zia, J. Appl. Polym. Sci., 28, 3849 (1983).

12. D. J. Hourston and Y. Zia, J. Appl. Polym. Sci., 29,
2951 (1984).

13. D. J. Hourston and Y. Zia, J. Appl. Polym. Sci., 29, 2963 (1984).

14. J. H. Saunders and K. C. Frisch, "Polyurethane Chemistry and Technology," Vol. I, Interscience, New York, N.Y., 1962, p 50.

15. N. D. Ghatge and V. B. Phadke, J. Appl. Polym. Sci., 11, 629 (1967).

16. J. A. Manson and L. H. Sperling, Macromolecules, 12, 360 (1979).

17. N. Devia, J. A. Manson, L. H. Sperling, and A. Conde, Polym. Eng., Sci., 19, 869 (1979).

18. L. H. Sperling, J. A. Manson, and M. A. Linne, $J$. Polym. Mater., 1, 54 (1984).

19. M. Patel and B. Suthar, Makromol. Chem., 187, 525 (1986).

20. M. Patel and B. Suthar, J. Appl. Polym. Sci., 33, 67 (1987).

21. M. Patel and B. Suthar, Angew Makromol. Chem., 149, 111 (1987).

22. M. Patel and B. Suthar, Eur. Polym. J., 23, 399 (1987).

23. M. Patel and B. Suthar, J. Polym. Sci., Polym. Chem. Ed., 25, 2251 (1987).

24. K. C. Frisch, D. Klempner, and S. K. Mukherjee, J. Appl. Polym. Sci., 18, 689 (1974).

25. K. C. Frisch, D. Klempner, and S. Midgal, J. Polym. Sci., Polym. Chem. Ed., 12, 885 (1974).

26. K. C. Frisch, D. Klempner, and S. Midgal, J. Appl. Polym. Sci., 19, 1983 (1975).

27. D. S. Lee and S. C. Kim, Macromolecules, 18, 2173 (1985).

28. L. E. Nielsen, "Mechanical Properties of Polymers," Reinhold Publishing Corporation, London, 1962.

29. J. K. Yeo, L. H. Sperling, and D. A. Thomas, Polym. Eng. Sci., 22, 190 (1982).

30. J. K. Yeo, L. H. Sperling, and D. A. Thomas, Polymer, 24, 307 (1983).

31. E. F. Cassidy, H. X. Xia, K. C. Frisch, and H. L. Frisch. J. Polym. Sci., Polym. Chem. Ed., 22, 2667 (1984). 